\begin{tabular}{|c|l|}
\hline Title & Improving the quality of waste derived char by removing ash \\
\hline Author(s) & Hwang, I. H.; Nakajima, D.; Matsuto, T.; Sugimoto, T. \\
\hline Citation & $\begin{array}{l}\text { Waste Management, 28(2), 424.434 } \\
\text { https://doi.org/10.1016/.wasman.2006.11.015 }\end{array}$ \\
\hline Issue Date & 2008 \\
\hline Doc URL & http://hdl.handle.net/2115/33052 \\
\hline Type & article (author version) \\
\hline File Information & matsuto3.pdf \\
\hline
\end{tabular}

Instructions for use 


\title{
Improving the quality of waste-derived char by removing ash
}

\author{
I. H. Hwang, D. Nakajima, T. Matsuto*, and T. Sugimoto ${ }^{\dagger}$ \\ Laboratory of Solid Waste Disposal Engineering, \\ Graduate School of Engineering, Hokkaido University, \\ Kita 13 Nishi 8, Kita-ku, Sapporo 060-8628, Japan \\ ${ }^{\dagger}$ Technical Development Department, Plant \& Environment \\ Headquarters, Mitsui Engineering \& Shipbuilding Co., Ltd., \\ 1 Yawatakaigan-dori, Ichihara, Chiba 290-8601, Japan
}

\footnotetext{
*Corresponding author.

Tel/Fax: +81-11-706-6828; E-mail: matsuto@eng.hokudai.ac.jp (T. Matsuto)

The English in this document has been checked by at least two professional editors, both native speakers of English. For a certificate, see:

http://www.textcheck.com/cgi-bin/certificate.cgi?id=8QwagM
} 


\section{Abstract}

This study characterized and removed ash from waste-derived char to improve the quality of char as fuel. Municipal solid waste (MSW) and automobile shredder residue (ASR) were carbonized at $450{ }^{\circ} \mathrm{C}$ and at $500{ }^{\circ} \mathrm{C}$ respectively in a rotary kiln with a nitrogen atmosphere for $1 \mathrm{~h}$. MSW and ASR char were subjected to sieving and pulverization-sieving to screen incombustibles and the ash-rich fraction, after which float-sink separation, froth floatation, and oil agglomeration were applied to remove ash from the char. The established target quality was less than $30 \%$ ash content and more than $20000 \mathrm{~kJ} / \mathrm{kg}$ heating value. However, the rate of combustibles recovery had to be lowered to produce a good quality of char along with a high heating value. MSW char attained the targeted quality level using froth floatation or oil agglomeration whereas neither separation method was able to make ASR-derived char satisfy the target.

Based on the assumption that particle properties of char are determined by the weight ratio of combustibles and ash, the densities of combustibles and ash in char were estimated using the results of float-sink separation, X-ray diffraction (XRD) analysis, and elemental content. To verify the above assumption, an energy dispersive X-ray/scanning electron microscope (EDX/SEM) analyzer was used to observe char particles.

Keywords: Ash removal, automobile shredder residue (ASR), carbonization, coal cleaning techniques, municipal solid waste (MSW). 


\section{Introduction}

Depleting fossil fuels and increasing waste amount have resulted in the promotion of energy recovery from solid waste. Incineration is one of the representative methods for energy recovery from wastes. Pyrolysis and gasification technologies also have been investigated to improve the energy efficiency as well as to increase the rate of waste-to-energy (Malkow, 2004).

Carbonization is a thermal process that produces char from organic materials in an inert atmosphere. Waste-derived char is considered as a substitute fuel for cement or paper production plants, which also has the potential to be used in coal fired power station (Matsuzawa et al., 2004).

However, large quantities of chlorine and ash are often deemed as obstacles to practical use of biomass or waste derived char because they are notorious for causing corrosion, fouling, deposition, slagging, sintering, and agglomeration during combustion (Arvelakis and Koukios, 2002). Most chlorine included in coal or char can be removed with a washing procedure (Chen and Pagano, 1986; Jenkins et al., 1998; Jensen et al., 2001). Our previous research indicated that repeated washing and carbonation in water could reduce the $1.5 \mathrm{wt} \%$ of chlorine contained in char derived from MSW to $0.2 \mathrm{wt} \%$ (Hwang et al., 2006). On the other hand, ash can be removed using a coal cleaning method because char shares many properties with coal.

Physical coal cleaning is generally based on density differences among particles and on hydrophilic or hydrophobic properties of particle surface (Tsunekawa et al., 1998; Ünal and Aktaş, 2001). Float-sink separation is usually accomplished using a fluid medium with a density intermediate to the materials being separated; particles lighter than the medium float and heavier ones sink (Scheirs, 1998). During froth 
floatation, hydrophobic particles attach to a frother, while hydrophilic ones are left in the solution as a tail. Oil agglomeration is accomplished by intensively mixing an oil and coal slurry to form aggregates. Differing surface hydrophobicity makes oil adhere to hydrophobic organic constituents, separating them from hydrophilic inorganic compounds (Shrauti and Arnold, 1995).

In this study, two types of char were subjected to ash removal tests. One was a char produced from municipal solid waste (MSW). Klass (1998) noted MSW could be one of most prospective sources for energy recovery among available biomass because of its large amount and well-established collection systems for centralized disposal. Many researchers have reported on the usefulness of MSW-derived char as fuel (Vassilev et al., 1999; Malkow, 2004; Matsuto et al., 2004; Matsuzawa et al., 2004; Hwang et al., 2006). The other type of char was derived from automobile shredder residue (ASR). In Japan, 700,000-800,000 tons of ASR are sent to landfills every year (JECS, 2005). The Law for the Recycling of End-of-Life Vehicles states that by the year 2015 , over $95 \%$ of ELVs must be recycled. According to the report of JECS (2005), about 70\% of ASR has to be recycled to achieve above goal.

Nourredine (2007) reviewed various material and thermal recycling techniques for ASR, including incineration, pyrolysis, injection into blast furnace, etc. Zolezzi et al. (2004) investigated conventional and fast pyrolysis of ASR with the reviews of previous ASR pyrolysis researches. However, their works focused on oil and gas products rather than char. In our past work (Hwang et al., 2006), ASR char contained about $60 \mathrm{wt} \%$ ash and $4 \mathrm{wt} \%$ chlorine so that a considerable amount of ash must be removed in order for it to be used as an alternative fuel.

Recovered char by coal cleaning methods was evaluated using the rate of combustibles recovery, ash content, and heating value. This study established a 
practical goal of less than $30 \%$ ash and more than $20000 \mathrm{~kJ} / \mathrm{kg}$ heating value. Char particles were investigated qualitatively by microscopic analyses too.

\section{Material and Methods}

\subsection{Preparation of char}

Figure 1 presents the entire experimental flow. Char derived from MSW was sampled at a pyrolysis-melting facility in Muroran, Japan. The MSW composition obtained from the facility was as follows: $45.8 \%$ paper, $21.9 \%$ plastics, $10.4 \%$ wood, $8.9 \%$ textiles, $6.8 \%$ glass and porcelain, $1.1 \%$ metal, $0.6 \%$ rubber and leather, and $4.5 \%$ miscellaneous materials. After shredding, the MSW was carbonized in a nitrogen-atmosphere rotary kiln at $450{ }^{\circ} \mathrm{C}$ for $1 \mathrm{~h}$. The produced char was cooled and then passed successively through a sieve, a magnetic separator, and a vertical air classifier. Around $5 \mathrm{~kg}$ of char was sampled at a char storage hopper.

ASR was obtained from an ELV disassembly and shredding plant. ELVs are first disassembled by hand to recover recyclable parts and hazardous components, after which the remaining body is first crushed coarsely and then shredded. This allows ferrous and nonferrous recyclable metal to be recovered, and the remaining residue is ASR. The composition of ASR obtained from the ELV disassembly and shredding plant was as follows: $30.5 \%$ plastics, $24.3 \%$ glass and porcelain, $12.3 \%$ metal, $12.2 \%$ rubber and leather, $7.2 \%$ textiles, $3.4 \%$ paper, $2.8 \%$ wood, and $7.3 \%$ miscellaneous material. Approximately $5 \mathrm{~kg}$ of ASR was collected and dried at $60{ }^{\circ} \mathrm{C}$. Dried ASR was loaded into a rotary kiln-type of reactor $(\mathrm{D} \times \mathrm{L}=150 \mathrm{~mm} \times 1200 \mathrm{~mm})$ 
using a screw feeder at the rate of $250 \mathrm{~g} / \mathrm{h}$ at the laboratory (Hwang et al., 2006). Carbonization temperature was $500{ }^{\circ} \mathrm{C}$ and nitrogen was used as a carrier gas at a rate of $11 \mathrm{~L} / \mathrm{min}$ to maintain a reducing atmosphere. The kiln's slope angle and rotation rate were adjusted to $0.8^{\circ}$ and $2 \mathrm{rpm}$, respectively, to maintain a retention time of $1 \mathrm{~h}$.

MSW- and ASR char were subjected to sieving and pulverization-sieving to screen incombustibles and the ash-rich fraction as shown Figure 1.

2.2 Coal cleaning methods for ash removal

Three kinds of coal cleaning methods were used to remove ash from char: floatsink separation, froth flotation, and oil agglomeration. The procedures are explained below.

- Float-sink separation: Distilled water was prepared as fluid with a density of 1.0 $\mathrm{g} / \mathrm{cm}^{3}$, and then a calcium chloride reagent (min 95.0\% purity; Kanto Chemical Co., Inc., Tokyo, Japan) was added to create fluid densities of $1.2 \mathrm{~g} / \mathrm{cm}^{3}$ and $1.4 \mathrm{~g} / \mathrm{cm}^{3}$. Char was added to fluid media in three $300 \mathrm{ml}$ bottles with lids to create liquid to solid ratios (L/S) such as 30, 40, and 60. After each bottle was lidded, it was shaken and allowed to settle for $24 \mathrm{~h}$. Float was then collected, after which remaining sink was separated from the liquid using a filtration process with a vacuum pump. Each fraction was rinsed three times with a total volume of $900 \mathrm{ml}$ distilled water. After float and sink were dried overnight at $80{ }^{\circ} \mathrm{C}$, they were each weighed.

- Froth flotation: Char was immersed in two samples of $400 \mathrm{ml}$ distilled water to produce values of 1 and $3 \mathrm{wt} \%$ respectively. To this char-water slurry, $20 \mu \mathrm{l} / \mathrm{L}$ methyl isobutyl carbinol (MIBC) was added as a frother and 0-1.5 $\mu \mathrm{l} / \mathrm{g}$-char of kerosene was added as a collector. Several drops of sodium hexametaphosphate (SHMP) were also 
added as a dispersing agent. Froth floatation was carried out using an agitator type of floatation machine with a $500 \mathrm{ml}$ rectangular cell. Rates of impeller rotation and aeration were set at $900 \mathrm{rpm}$ and $0.7 \mathrm{~L} / \mathrm{min}$, respectively. At constant intervals during the 10 min floatation, particles adhering to the bubble surface were recovered as froth. When floatation was complete, remaining tail particles were separated using filtration with a vacuum pump. Froth and tail were dried overnight at $80{ }^{\circ} \mathrm{C}$ and then each was weighed.

- Oil agglomeration: Agglomeration was carried out using a commercial blender (National MX-V200; Matsushita Electric Industrial Co., Ltd., Osaka, Japan) equipped with a $1000 \mathrm{ml}$ glass vessel and a rotation controller. $200 \mathrm{ml}$ distilled water and $5 \mathrm{~g}$ char were placed in the vessel, and then between 2 and $16 \mathrm{ml}$ of kerosene (0.4-3.2 $\mathrm{ml} / \mathrm{g}$-char) was added to this char-water slurry as bridging oil. The mixture was blended at $10000 \mathrm{rpm}$ for $10 \mathrm{~min}$ to produce agglomerates. Agglomerates in the vessel were separated from water and tailings by screening with a $150 \mu \mathrm{m}$ sieve. Agglomerates collected in the vessel were rinsed with distilled water to remove surface tails completely. After washing with water at $8000 \mathrm{rpm}$ for $5 \mathrm{~min}$, the mixture was screened again using a $150 \mu \mathrm{m}$ sieve. Agglomerates remaining on the sieve were collected and dried overnight at $80{ }^{\circ} \mathrm{C}$, after which they were weighed.

\subsection{Evaluation of char quality}

After conducting the coal cleaning methods, recovered char was evaluated in terms of combustible recovery ratio, ash content, and higher heating value of recovered char. Rates of combustibles recovery were determined using equation 1 : 


$$
\text { Rate of combustibles recovery }(\%)=\frac{100-A s h_{r}}{100-A s h_{0}} \times \frac{W_{r}}{W_{0}}
$$

where $A s h_{0}$ and $A s h_{r}$ represent the weight percent of ash in char less than $125 \mu \mathrm{m}$ and that in char recovered using the coal cleaning methods, respectively; $W_{0}$ and $W_{r}$ represent the weight of char less than $125 \mu \mathrm{m}$ and that of char recovered using the coal cleaning methods, respectively.

Higher heating value (HHV) was estimated by substituting the weight percentages in char of fixed carbon (FC) and volatile matter (VM) using equation 2 (Hwang et al., 2006):

$$
\mathrm{HHV}_{\text {Estimated }}[\mathrm{kJ} / \mathrm{kg}]=(32750 \times \mathrm{FC}+19598 \times \mathrm{VM}) \div 100
$$

\subsection{Analyses}

Fixed carbon, volatile matter, and ash were measured by the method of proximate analysis for coal and coke (JIS M 8812, 2004). Carbon, hydrogen, and nitrogen were measured using an elemental analyzer (CHN recorder MT-5; Yanaco Co., Ltd.). To determine sulfur content, the sulfuric oxide generated during incineration was absorbed in a hydrogen peroxide solution and its concentration was measured by ion chromatography (DX-500; Dionex Co.). Chlorine was determined using an incineration method with a tubular quartz reactor (JIS Z 7302-6, 1999) and its concentration was measured by an absorption spectrophotometer (U-1101; Hitachi Co.) according to the mercuric thiocyanate method (JIS K 0107, 2002). 
To determine metal content, a microwave-assisted acid digestion method (US EPA, 1996) was used to destroy the solid matrix in $0.5 \mathrm{~g}$ of char. After digestion, residual material was collected and filtered using $1 \mu \mathrm{m}$ pore filter paper. Concentrations of iron, calcium, aluminum, magnesium, sodium, potassium, zinc, lead, and copper in filtrate were analyzed using flame atomic absorption spectrometry (Metals except aluminum: Z-8200, Hitachi Co.; aluminum: A-1000/A-2000, Hitachi Co.).

To determine silicon content, 10-20 $\mathrm{g}$ of char was placed in a crucible and incinerated in a muffle furnace at $800{ }^{\circ} \mathrm{C}$ for $2 \mathrm{~h}$. After being cooled in a desiccator, 5 $\mathrm{g}$ of the residue was sampled and digested using an acid solution of $\mathrm{HNO}_{3} / \mathrm{HCl}=3$ at $120{ }^{\circ} \mathrm{C}$ for $24 \mathrm{~h}$. The digested solution was evaporated to near dryness and then cooled to room temperature. At this point, $20 \mathrm{ml}$ of $3 \mathrm{~N} \mathrm{HNO}_{3}$ was added and evaporated at $80{ }^{\circ} \mathrm{C}$ for $30 \mathrm{~min}$. After cooling, residue was filtrated with $1 \mu \mathrm{m}$ pore filter paper and placed in a crucible with filter paper and incinerated at $1000{ }^{\circ} \mathrm{C}$ for $1.5 \mathrm{~h}$. After being cooled in a desiccator, the residue was weighed as silica.

Heating value was measured using a bomb calorimeter (automobile-calculating calorimeter CA-4PJ; Shimadzu Co., Kyoto, Japan).

Element distribution on char surface was investigated under a scanning electron microscope (SEM) equipped with an energy dispersive X-ray (EDX) analyzer (SSX500/SEDX-500; Shimadzu Co.). An X-ray diffraction (XRD) analyzer (JDX-3500; JEOL Ltd.) was used to determine ash composition qualitatively and quantitatively.

\section{Results and Discussion}




\subsection{Characteristics of MSW- and ASR char}

First, char particles larger than $5.6 \mathrm{~mm}$ were removed as incombustibles, as shown in Figure 1. The particles smaller than $5.6 \mathrm{~mm}$ was milled and then classified into the following sizes: $<53 \mu \mathrm{m}, 53-125 \mu \mathrm{m}, 125-210 \mu \mathrm{m}, 210 \mu \mathrm{m}-1 \mathrm{~mm}$, and 1-5.6 $\mathrm{mm}$. Proximate analysis results for each fraction indicated that the fraction of particles larger than $125 \mu \mathrm{m}$ corresponded to incombustibles or ash-rich materials in both types of char. Char particles smaller than $125 \mu \mathrm{m}$ were prepared for further qualityimprovement experiments (Figure 1).

Table 1 lists char yield depending on particle sizes and physicochemical properties of MSW and ASR char particles smaller than $125 \mu \mathrm{m}$. Assuming an initial char weight of 100, MSW and ASR char particles smaller than $125 \mu \mathrm{m}$ would yield 80.6 and $64.5 \mathrm{wt} \%$, respectively. MSW and ASR char had ash contents and HHVs of $38.0 \mathrm{wt} \%, 18010 \mathrm{~kJ} / \mathrm{kg}$ and $68.7 \mathrm{wt} \%, 8801 \mathrm{~kJ} / \mathrm{kg}$, respectively. As mentioned in section 2.1, ASR was mainly composed of plastics, rubber, metals, and glass. Since plastics volatilize easily at low temperatures, ASR char presents relatively high ash content.

The major inorganic elements in char samples were silicon, calcium, iron, and aluminum. ASR char contained greater quantities of zinc $(3.31 \mathrm{wt} \%)$ and copper $(0.25 \mathrm{wt} \%)$ compared to MSW char.

3.2. Variation in char quality resulting from different coal cleaning methods

\subsubsection{MSW char}


Figure 2 presents the mass balance and composition of recovered- and rejected fraction resulting from float-sink separation, froth floatation, and oil agglomeration of MSW char.

The float-sink separation method led to various weight percents and compositions of float and sink, depending on media density, $1.0,1.2$, and $1.4 \mathrm{~g} / \mathrm{cm}^{3}$ under $\mathrm{L} / \mathrm{S}=30$ (Figure 2a). The float amount increased as the medium density increased; however, the quality of recovered char was unchanged or worsened (see Figure 4a). When L/S ratios were 30, 40, and 60, the weight fractions of float were 67.6, 64.1, and $42.9 \mathrm{wt} \%$ at $1.0 \mathrm{~g} / \mathrm{cm}^{3}$ medium density. As the $\mathrm{L} / \mathrm{S}$ ratio increased to 60 , the weight percent of float considerably decreased. Under conditions of $1.0 \mathrm{~g} / \mathrm{cm}^{3}$ and $\mathrm{L} / \mathrm{S}=30$ media density, ash content was lowered from 38 to $31.1 \mathrm{wt} \%$

During froth separation, the weight percent of froth increased when kerosene was added as a collector at $1 \mathrm{wt} \%$ char input concentration (Figure $2 \mathrm{~b}$ ). The rate of combustibles recovery was raised by using kerosene but ash content of froth increased too (see Figure 4a). When char input concentration increased to $3 \mathrm{wt} \%$, kerosene addition was ineffective to improve the rate of combustibles recovery (see Figure 4a).

The oil agglomeration method resulted in a higher rate of combustibles recovery with an increased supply of kerosene as bridging oil, but agglomerate ash content also increased as shown in Figure 4a. This result is consistent with the findings of previous studies (Shrauti and Arnold, 1995; Alonso et al., 1999), which indicated that ash removal decreased under conditions of greater oil addition because of agglomerating less hydrophobic particles.

Figure 4 illustrates a higher quality of char led to a lower rate of combustible recovery. For example, during the oil agglomerate method, addition of $0.4 \mathrm{ml} / \mathrm{g}$-char of kerosene decreased the weight percentage of ash in MSW char to 21\%; heating 
value increased to $21730 \mathrm{~kJ} / \mathrm{kg}$ (FC: $47.5 \%$ and $\mathrm{VM}: 31.5 \%$ ) while the rate of combustible recovery was merely $20.7 \%$ (Figure $4 a$ ).

\subsubsection{ASR char}

Figure 3 presents the mass balance and composition of recovered- and rejected fraction resulting from float-sink separation, froth floatation, and oil agglomeration of ASR char.

Similar to results for MSW char, the rate of combustibles recovery of float increased with an increased density in medium fluid, but ash content grew together (Figure 3a). Under media density conditions of $1.0 \mathrm{~g} / \mathrm{m}^{3}$ and $\mathrm{L} / \mathrm{S}=30$, it was possible to reduce the weight fraction of ash to $63.1 \%$. This was not a conspicuous improvement because the ash content of input ASR char was $68.7 \%$ (See Figure $4 \mathrm{~b}$ )

During froth separation (Figure 3b), the rate of combustibles recovery and froth ash content increased together as kerosene supplies increased (see Figure 4b). Kerosene improved the rate of combustibles recovery at $1 \mathrm{wt} \%$ char input concentration but it became ineffective at $3 \mathrm{wt} \%$ char input concentration (see Figure 4b).

The oil agglomeration method produced higher rates of combustible recovery and greater agglomerate ash content when kerosene supply increased (Figure 3c and Figure 4b). Shrauti and Arnold (1995) noted that high ash content led to low agglomerate recovery by allowing water to penetrate into agglomerates easily, consequently weakening particle bonds.

Figure $4 \mathrm{~b}$ presented that the weight of ash in ASR char decreased from $68.7 \%$ to $55 \%$, but the rate of combustible recovery was no more than $15 \%$ and heating values 
were still much less than $20000 \mathrm{~kJ} / \mathrm{kg}$. Despite all efforts to separate ash from ASR char, it was impossible to achieve the goal of less than $30 \%$ ash content.

\subsection{Identification of ash presence in char}

\subsubsection{The composition of inorganic matter in recovered and rejected fractions}

The composition of inorganic matter was investigated in recovered and rejected fractions such as float and sink or froth and tail. Each fraction was subjected to $\mathrm{Si}, \mathrm{Ca}$, $\mathrm{Al}, \mathrm{Zn}$, and $\mathrm{Fe}$ analyses. When their compositions were converted into percentages, no significant differences appeared between recovered and rejected fractions except for $\mathrm{Si}$.

For example, in the case of MSW char divided by float-sink separation, weight fractions of $\mathrm{Si}, \mathrm{Ca}, \mathrm{Al}, \mathrm{Fe}$, and $\mathrm{Zn}$ were $47,31,12,9$, and $1 \%$ for the float at $1.0 \mathrm{~g} / \mathrm{cm}^{3}$ media fluid, and $58,26,8,7$, and $1 \%$ for the sink at $1.4 \mathrm{~g} / \mathrm{cm}^{3}$ media fluid. The corresponding values of ASR char were 48, 13, 5, 25, and $9 \%$ for the float at 1.0 $\mathrm{g} / \mathrm{cm}^{3}$ media fluid, and $64,10,4,17$, and $5 \%$ for the sink at $1.4 \mathrm{~g} / \mathrm{cm}^{3}$ media fluid. This tendency was also observed in froth and tail fractions produced during froth separation. These results indicate that ash components are merely transferred into recovered or rejected fractions without remarkable constituent variation when coal cleaning methods are performed.

\subsubsection{Estimation of combustible and ash densities using the result of float-sink} separation

We established a hypothesis about ash presence in char: combustibles (fixed carbon+volatile matter) and ash constituents are originally both homogeneous, 
regardless recovered- and rejected fractions. Because combustibles and ash are combined together and thereby exist as complex forms in char particles, char particle properties are determined by the combustibles and ash weight ratio; particles containing a higher ratio of combustibles may float in media fluid, attach to froth, and be agglomerated due to the lightness and hydrophobic characteristics of the combustible fraction.

Based on our assumption, we estimated combustibles and ash densities in char using experimental data from the float-sink separation method under the condition of $\mathrm{L} / \mathrm{S}=30$. Figure 5 illustrates the general estimation procedure. In Figure 5(a), $\mathrm{C}_{1}$ and $\mathrm{A}_{1}$ indicate the combustibles and ash weight in particles with densities less than 1.0 $\mathrm{g} / \mathrm{cm}^{3}$. The float in a $1.2 \mathrm{~g} / \mathrm{cm}^{3}$ medium has a density lower than $1.2 \mathrm{~g} / \mathrm{cm}^{3}$, and thus subtracting $C_{1}$ and $A_{1}$ from this float reveals that $C_{2}$ and $A_{2}$ must be the combustibles and ash fraction of particles with densities ranging from 1.0 to $1.2 \mathrm{~g} / \mathrm{cm}^{3}$. The same method can be applied to particles of 1.2 to $1.4 \mathrm{~g} / \mathrm{cm}^{3}$ to obtain $\mathrm{C}_{3}$ and $\mathrm{A}_{3}$. Finally, particles with densities greater than $1.4 \mathrm{~g} / \mathrm{cm}^{3}$ can be obtained from the sink at 1.4 $\mathrm{g} / \mathrm{cm}^{3}$, and characterized as $\mathrm{C}_{4}$ and $\mathrm{A}_{4}$. As a result, the particle density distribution is obtained as shown in Figure 5(b).

The average density of $i$-th particles can be estimated using the following equation:

$$
\overline{\rho_{i}}=\frac{C_{i}+A_{i}}{\frac{C_{i}}{\rho_{C}}+\frac{A_{i}}{\rho_{A}}}
$$


where $\rho_{C}$ and $\rho_{A}$ are the average densities of combustibles and ash, respectively; $C_{i}$ and $A_{i}$ are the weight fractions of combustibles and ash in the $i$-th group of particles, respectively.

If average densities, $\overline{\rho_{1}}, \overline{\rho_{2}}, \overline{\rho_{3}}$, and $\overline{\rho_{4}}$ are assumed to be $0.9,1.1 .1 .3$, and $1.5 \mathrm{~g} / \mathrm{cm}^{3}$, respectively, the least squares method can be used to determine $\rho_{C}$ and $\rho_{A}$ to minimize error between assumed and estimated average densities. The resulting $\rho_{C}$ and $\rho_{A}$ of MSW char were estimated at 0.79 and $2.61 \mathrm{~g} / \mathrm{cm}^{3}$, whereas those of ASR char were estimated at 0.43 and $3.15 \mathrm{~g} / \mathrm{cm}^{3}$ (Table 2).

\subsubsection{Estimation of ash composition and density using the result of XRD analysis}

An XRD analysis was conducted for a qualitative analysis of ash in char. When specific peaks are frequently observed in char, they usually indicate the presence of corresponding compounds. The peaks in XRD analyses identified major inorganic compounds in char, as shown in Table 3: $\mathrm{SiO}_{2}$ (quartz), $\mathrm{Mg}_{2} \mathrm{Al}_{4} \mathrm{Si}_{5} \mathrm{O}_{18}$ (indialite), $\mathrm{Fe}_{2} \mathrm{SiO}_{4} \quad$ (fayalite), $\quad \mathrm{Ca}_{3} \mathrm{Al}_{2}(\mathrm{OH})_{12}$ (katoite), $\mathrm{CaAl}_{2} \mathrm{Si}_{2} \mathrm{O}_{8} \quad$ (anorthite), $\mathrm{Zn}_{2} \mathrm{SiO}_{4}$ (willemite), and $\mathrm{Fe}_{2} \mathrm{O}_{3}$ (maghemite).

Using the elemental content in Table 1, the MSW and ASR char ash composition could be estimated qualitatively and quantitatively. Ash density could also be calculated based on estimated ash composition.

The following procedure was used to estimate ash composition in MSW char: the weight of single elements $(\mathrm{Cu}, \mathrm{Pb}$, and $\mathrm{Zn})$, chlorides $(\mathrm{NaCl}$ and $\mathrm{KCl})$, maghemite $\left(\mathrm{Fe}_{2} \mathrm{O}_{3}\right)$, and indialite $\left(\mathrm{Mg}_{2} \mathrm{Al}_{4} \mathrm{Si}_{5} \mathrm{O}_{18}\right)$ were readily determined from the elemental content of copper, lead, zinc, sodium, potassium, iron, and magnesium shown in Table 1 because they were single substances or contained an available element. After 
determining indialite $\left(\mathrm{Mg}_{2} \mathrm{Al}_{4} \mathrm{Si}_{5} \mathrm{O}_{18}\right)$, the residual weight of $\mathrm{Al}$ was allocated to anorthite $\left(\mathrm{CaAl}_{2} \mathrm{Si}_{2} \mathrm{O}_{8}\right)$. Finally, quartz $\left(\mathrm{SiO}_{2}\right)$ and calcium carbonate $\left(\mathrm{CaCO}_{3}\right)$ were each determined using the stoichiometric relationship among silicon and calcium. The ash composition in ASR char was estimated using the same procedure.

Table 3 lists the estimated ash composition and density in MSW and ASR char. Quartz was the most abundant inorganic compound, and was estimated at $14.72 \%$ in MSW char and at $16.43 \%$ in ASR char. Calculated densities based on estimated ash composition in MSW and ASR char resulted in values of 2.81 and $3.16 \mathrm{~g} / \mathrm{cm}^{3}$, respectively. Two values were close to densities obtained using experimental data from float-sink separation (MSW char: $2.61 \mathrm{~g} / \mathrm{cm}^{3}$; ASR char: $3.15 \mathrm{~g} / \mathrm{cm}^{3}$, shown in Table 2); these results indicate that the hypotheses presented in section 3.3.2 about the presence of char particles are correct.

\subsubsection{SEM/EDX images of MSW and ASR char}

A small amount of char particles was dispersed by ethanol and completely dried on a carbon plate, after which the plate was inserted in a SEM/EDX analyzer to reveal images of the particles and elemental distribution of carbon, silicon, calcium, aluminum, and iron.

Figure 6 presents SEM/EDX images of both MSW and ASR char particles smaller than $125 \mu \mathrm{m}$. According to 300 and 1500 multiple images, char particles have diameters of approximately $8 \mu \mathrm{m}$ (Figure 6a and Figure 6d). 1500 multiple EDX images show that most particles present as complex substances of carbon and inorganic constituents combined (Figure 6c and 6f). Char particles were not segregated completely to single carbon or inorganic substances even after being milled for $1 \mathrm{~h}$. 
Figure 7 presents SEM images of particles after they were immersed in water. MSW and ASR char were each soaked in water, dropped on carbon plates using a spuit, and dried as they fell; particles became coagulated masses. These results indicate that wet separation using an aqueous solution likely reduces the efficiency of ash removal from char due to particle coagulation.

\section{Conclusions}

MSW- and ASR-derived char were subjected to ash removal for the purpose of improving quality of char as fuel. By separating the fraction of char particles larger than $5.6 \mathrm{~mm}$ and particles larger than $125 \mu \mathrm{m}$ after milling, $19.4 \%$ and $35.5 \%$ of MSW- and ASR char were rejected as an ash-rich fraction.

Results of using float-sink separation, froth flotation, and oil agglomeration methods on char particles smaller than $125 \mu \mathrm{m}$ indicated that a good quality of char with high heating values required a lower combustibles recovery rate. For MSWderived char, the targeted quality level $(20000 \mathrm{~kJ} / \mathrm{kg}$ heating value and $30 \%$ ash content) was attained using froth floatation or oil agglomeration. However, neither separation method was able to make ASR-derived char satisfy the target; ASR char still had ash content and heating values in the range of 55 to $67 \%$ and 8630 to 12500 $\mathrm{kJ} / \mathrm{kg}$ respectively.

Based on the assumption that properties of char particles depend on their combustibles and ash weight ratio, ash and combustibles densities were determined using the results of float-sink separation. MSW char had estimated combustible and ash densities of 0.79 and $2.61 \mathrm{~g} / \mathrm{cm}^{3}$, respectively, while the corresponding values for 
ASR char were 0.43 and $3.15 \mathrm{~g} / \mathrm{cm}^{3}$, respectively. The calculated densities based on ash composition estimated using XRD peaks and on the elemental content of MSW and ASR char resulted in values of 2.81 and $3.16 \mathrm{~g} / \mathrm{cm}^{3}$, respectively, indicating that our hypothesis about char particles was correct.

Results of the EDX/SEM analysis indicated that char particles were not segregated to single substances even after being milled for $1 \mathrm{~h}$. Moreover, char particles have a tendency to coagulate in water. These characteristics indicate that wet separation using an aqueous solution likely reduces efficiency due to particle coagulation.

\section{Acknowledgments}

This study was funded by the Mitsui Engineering \& Shipbuilding Co., Ltd.

\section{References}

Alonso, M.I, Valdés, A.F., Martínez-Tarazona, R.M., Garcia, A.B., 1999. Coal recovery from coal fines cleaning wastes by agglomeration with vegetable oils: Effects of oil type and concentration. Fuel, 78, 753-759.

Arvelakis, S., Koukios, E.G., 2002. Physicochemical upgrading of agroresidues as feedstocks for energy production via thermochemical conversion methods. Biomass and Bioenergy, 22, 331-348. 
Chen, H.L., Pagano, M., 1986. The removal of chlorine from Illinois coal by high temperature leaching. Fuel Processing Technology, 13, 261-269.

Hwang, I.H., Matsuto, T., Tanaka, N., 2006. Water-soluble characteristics of chlorine in char derived from municipal solid wastes. Waste Management, 26, 571-579.

Hwang, I.H., Matsuto, T., Tanaka, N., Sasaki, Y., Tanaami, K., 2007. Characterization of char derived from various types of solid wastes from the standpoint of fuel recovery and pretreatment before landfilling. Waste Management, 27, 1155-1166.

JESC, 2005. Technical review for ASR recycling and reuse. Japan Environmental Sanitation Center, Kawasaki, Japan.

Jenkins, B.M., Baxter, L.L., Miles, T.R., Jr., Miles, T.R., 1998. Combustion properties of biomass. Fuel Processing Technology, 54, 17-46.

Jensen, P.A., Sander, B., Dam-Johansen, K., 2001. Removal of K and Cl by leaching of straw char. Biomass and Bioenergy, 20, 447-457.

JISC, 1999. JIS Z 7302-6: Densified refuse derived fuel-Part 6: Test method for total chlorine contents, Japanese Industrial Standards Committee, Tokyo.

JISC, 2002. JIS K 0107: Methods for determination of hydrogen chloride in flue gas, Japanese Industrial Standards Committee, Tokyo.

JISC, 2004. JIS M 8812: Coal and coke-Methods for proximate analysis, Japanese Industrial Standards Committee, Tokyo.

Klass, D. L., 1998. Biomass for Renewable Energy, Fuel, and Chemicals. Academic Press: San Diego, CA.

Malkow, T., 2004. Novel and innovative pyrolysis and gasification technologies for energy efficient and environmentally sound MSW disposal. Waste Management, $24,53-79$. 
Matsuto, T., Tanaka, N., Kakuta, Y., Tojo, Y., Matsuo, T., 2004. Carbonization of household waste for recycling and thermal pre-treatment for landfill disposal. Haikibutu-Gakkaisi, 15, 408-417.

Matsuzawa, Y., Ayabe, M., Nishino, J., Kubota, N., Motegi, M., 2004. Evaluation of char fuel ratio in municipal pyrolysis waste. Fuel, 83, 1675-1687.

Nourreddine, M., 2007. Recycling of auto shredder residue. Journal of Hazardous Materials, 139, 481-490.

Scheirs, J., 1998. Polymer Recycling. John Wiley \& Sons: New York, NY.

Shrauti, S.M., Arnold, D.W., 1995. Recovery of waste fine coal by oil agglomeration. Fuel, 74, 459-465.

Tsunekawa, M., Kon, Y., Ito, M., Hirajima, T., Hiroyoshi, N., 1998. A method to characterize floatation performance of fine coal and estimate its liberation. Shigen-to-Sozai, 114, 421-425.

Ünal, İ., Aktaş, Z., 2001. Effect of various bridging liquids on coal fines agglomeration performance. Fuel Processing Technology, 69, 141-155.

US EPA, 1996. Test Methods for Evaluating Solid Waste, Physical/Chemical Methods SW-846 Method 3052: Microwave assisted acid digestion of siliceous and organically based matrices. Office of Solid Waste's manual of EPAapproved analytical methods, Washington, DC.

Vassilev, S.V., Braekman-Danheux, C., Laurent, P., 1999. Characterization of refusederived char from municipal solid waste. 1. Phase-mineral and chemical composition. Fuel Processing Technology, 59, 95-134.

Zolezzi, M., Nicolella, C., Ferrara, S., Iacobucci, C., Rovatti, M., 2004. Conventional and fast pyrolysis of automobile shredder residues (ASR). Waste Management, 24, 691-699. 
Table 1. Char yield, composition, and heating value

\begin{tabular}{|c|c|c|}
\hline & MSW char & ASR char \\
\hline \multicolumn{3}{|l|}{ Char yield (wt $\%)$} \\
\hline$>5.6 \mathrm{~mm}^{\mathrm{a}}$ & 10.3 & 21.9 \\
\hline $0.125-5.6 \mathrm{~mm}^{\mathrm{b}}$ & 9.1 & 13.6 \\
\hline$<0.125 \mathrm{~mm}^{\mathrm{b}}$ & 80.6 & 64.5 \\
\hline \multicolumn{3}{|l|}{ Composition of char under $125 \mu \mathrm{m}$ (wt\%-dry) } \\
\hline Ash & 38.0 & 68.7 \\
\hline Fixed carbon & 36.4 & 15.1 \\
\hline Volatile matter & 25.6 & 16.2 \\
\hline Carbon & 43.3 & 20.2 \\
\hline Hydrogen & 2.7 & 1.3 \\
\hline Nitrogen & 1.7 & 0.8 \\
\hline Sulfur & 0.3 & 0.7 \\
\hline Chlorine & 1.6 & 3.0 \\
\hline Silicon & 9.52 & 17.41 \\
\hline Iron & 1.49 & 8.77 \\
\hline Calcium & 5.92 & 7.93 \\
\hline Aluminum & 1.94 & 3.42 \\
\hline Magnesium & 0.43 & 1.34 \\
\hline Sodium & 0.61 & 0.45 \\
\hline Potassium & 0.11 & 0.24 \\
\hline Zinc & 0.17 & 3.31 \\
\hline Lead & 0.12 & 0.34 \\
\hline Copper & 0.02 & 0.25 \\
\hline Higher heating value of char under $125 \mu \mathrm{m}(\mathrm{kJ} / \mathrm{kg}$-dry $)$ & 18010 & 8801 \\
\hline
\end{tabular}

${ }^{\mathrm{a}}$ Before pulverization.

${ }^{\mathrm{b}}$ After pulverization of char under $5.6 \mathrm{~mm}$. 
Table 2. Estimated density of combustibles and ash using experimental results from float-sink separation under mediums of 1.0, 1.2, and 1.4 $\mathrm{g} / \mathrm{cm}^{3}$ at $\mathrm{L} / \mathrm{S}=30$.

$\rho<1.0 \quad 1.0<\rho<1.2 \quad 1.2<\rho<1.4 \quad \rho>1.4$

\begin{tabular}{|c|c|c|c|c|}
\hline \multicolumn{5}{|l|}{ MSW char } \\
\hline Weight fraction of combustibles $i(\mathrm{wt} \%)$ & $\mathrm{C}_{1}=46.6$ & $\mathrm{C}_{2}=7.6$ & $\mathrm{C}_{3}=4.6$ & $\mathrm{C}_{4}=3.4$ \\
\hline Weight fraction of ash $i(\mathrm{wt} \%)$ & $\mathrm{A}_{1}=21.0$ & $\mathrm{~A}_{2}=4.4$ & $\mathrm{~A}_{3}=4.6$ & $\mathrm{~A}_{4}=7.8$ \\
\hline Assumed average density $\left(\overline{\rho_{i}}\right)$ & 0.9 & 1.1 & 1.3 & 1.5 \\
\hline Calculated average density $\left(\overline{\rho_{i, c a l}}\right)$ & 1.00 & 1.06 & 1.21 & 1.53 \\
\hline Estimated combustible density $\left(\rho_{C}\right)$ & \multicolumn{4}{|c|}{0.79} \\
\hline Estimated ash density $\left(\rho_{A}\right)$ & \multicolumn{4}{|c|}{2.61} \\
\hline \multicolumn{5}{|l|}{ ASR char } \\
\hline Weight fraction of combustibles $i(\mathrm{wt} \%)$ & $\mathrm{C}_{1}=20.3$ & $\mathrm{C}_{2}=5.0$ & $\mathrm{C}_{3}=3.6$ & $\mathrm{C}_{4}=2.2$ \\
\hline Weight fraction of ash $i$ (wt \%) & $\mathrm{A}_{1}=34.7$ & $\mathrm{~A}_{2}=12.0$ & $\mathrm{~A}_{3}=11.2$ & $\mathrm{~A}_{4}=10.9$ \\
\hline Assumed average density $\left(\overline{\rho_{i}}\right)$ & 0.9 & 1.1 & 1.3 & 1.5 \\
\hline Calculated average density $\left(\overline{\rho_{i, c a l}}\right)$ & 0.94 & 1.10 & 1.23 & 1.53 \\
\hline Estimated combustible density $\left(\rho_{C}\right)$ & \multicolumn{4}{|c|}{0.43} \\
\hline Estimated ash density $\left(\rho_{A}\right)$ & \multicolumn{4}{|c|}{3.15} \\
\hline
\end{tabular}

$\mathrm{C}_{1}-\mathrm{C}_{4}$ and $\mathrm{A}_{1}-\mathrm{A}_{4}$ are referred from Figure 5 . 
Table 3. Estimated ash composition and density in MSW and ASR char based on XRD analyses and elemental content.

\begin{tabular}{|c|c|c|c|c|}
\hline \multirow[t]{2}{*}{ Composition } & \multirow[t]{2}{*}{ Formula } & \multirow{2}{*}{$\begin{array}{l}\text { Density } \\
\left(\mathrm{g} / \mathrm{cm}^{3}\right)\end{array}$} & \multicolumn{2}{|c|}{$\begin{array}{l}\text { Estimated weight fraction } \\
(\mathrm{wt} \%)\end{array}$} \\
\hline & & & MSW char & ASR char \\
\hline Quartz & $\mathrm{SiO}_{2}$ & 2.70 & 14.72 & 16.43 \\
\hline Indialite & $\mathrm{Mg}_{2} \mathrm{Al}_{4} \mathrm{Si}_{5} \mathrm{O}_{18}$ & 2.51 & 5.22 & 16.11 \\
\hline Fayalite & $\mathrm{Fe}_{2} \mathrm{SiO}_{4}$ & 4.39 & 2.71 & - \\
\hline Katoite & $\mathrm{Ca}_{3} \mathrm{Al}_{2}(\mathrm{OH})_{12}$ & 2.76 & - & 3.12 \\
\hline Anorthite & $\mathrm{CaAl}_{2} \mathrm{Si}_{2} \mathrm{O}_{8}$ & 2.73 & 5.03 & - \\
\hline Calcium carbonate & $\mathrm{CaCO}_{3}$ & 2.71 & 12.98 & 14.39 \\
\hline Willemite & $\mathrm{Zn}_{2} \mathrm{SiO}_{4}$ & 4.05 & - & 5.64 \\
\hline Maghemite & $\mathrm{Fe}_{2} \mathrm{O}_{3}$ & 5.24 & - & 12.54 \\
\hline Halite & $\mathrm{NaCl}$ & 2.16 & 1.56 & 1.14 \\
\hline Sylvite & $\mathrm{KCl}$ & 1.98 & 0.21 & 0.46 \\
\hline Hydrophilite & $\mathrm{CaCl}_{2}$ & 2.15 & - & 3.27 \\
\hline Silicon & $\mathrm{Si}$ & 2.34 & - & 5.15 \\
\hline Zinc & $\mathrm{Zn}$ & 7.12 & 0.17 & - \\
\hline Lead & $\mathrm{Pb}$ & 11.34 & 0.12 & 0.34 \\
\hline Copper & $\mathrm{Cu}$ & 8.93 & - & 0.25 \\
\hline \multicolumn{2}{|l|}{ Total weight fraction } & & $\Sigma 42.72$ & $\Sigma 78.84$ \\
\hline \multicolumn{2}{|c|}{ Estimated ash density $\left(\rho_{A}\right)$} & & 2.81 & 3.16 \\
\hline
\end{tabular}

-: Not detected 


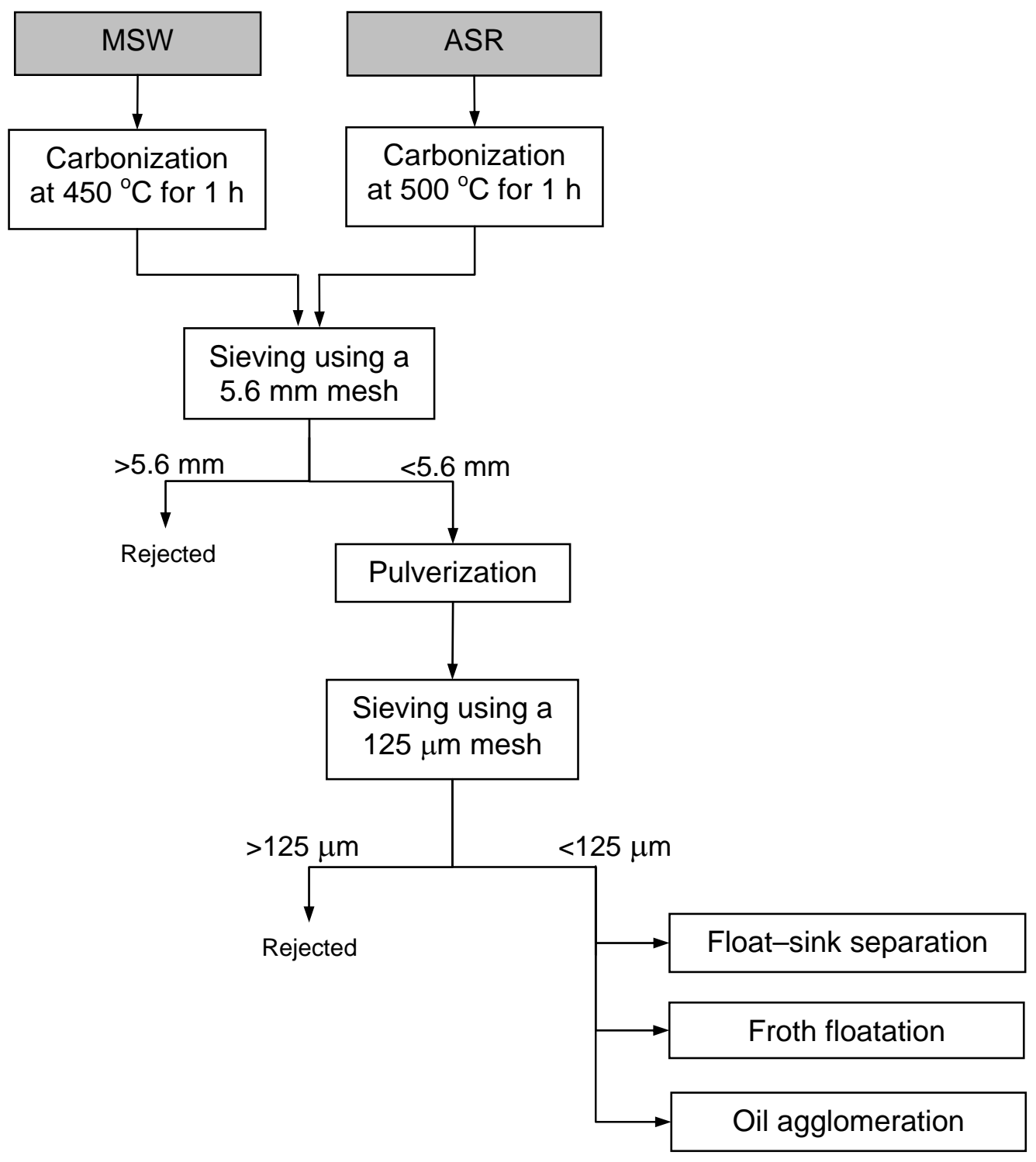

Figure 1. Experimental flow. 


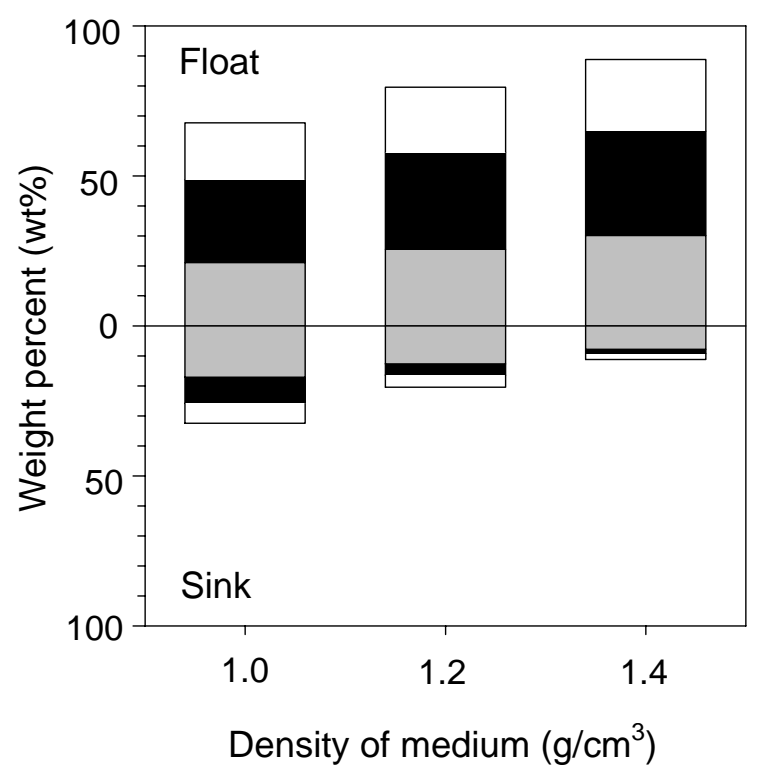

(a) Float-sink separation, L/S $=30$.

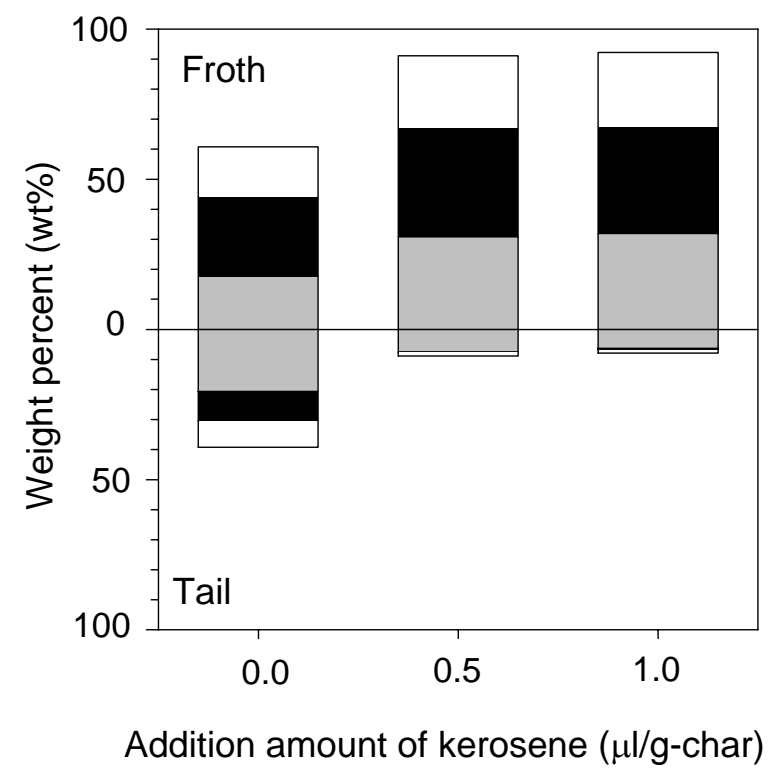

(b) Froth floatation, wt $=1 \%$.

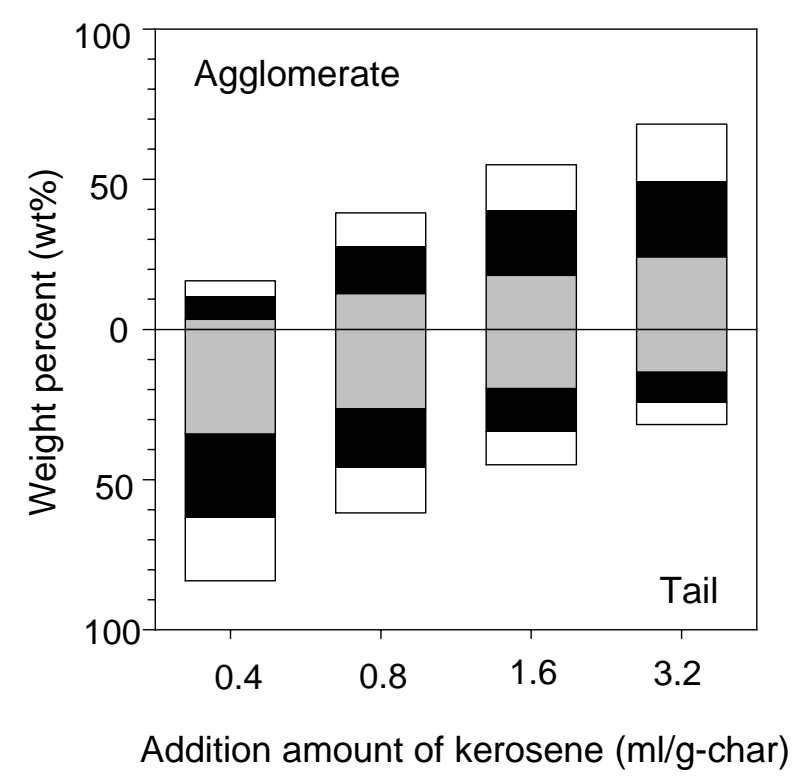

(c) Oil agglomeration.

Volatile matter

Fixed carbon

Ash

Figure 2. Mass balance and composition of recovered- and rejected MSW char by the application of float-sink separation, froth floatation, and oil agglomeration. 


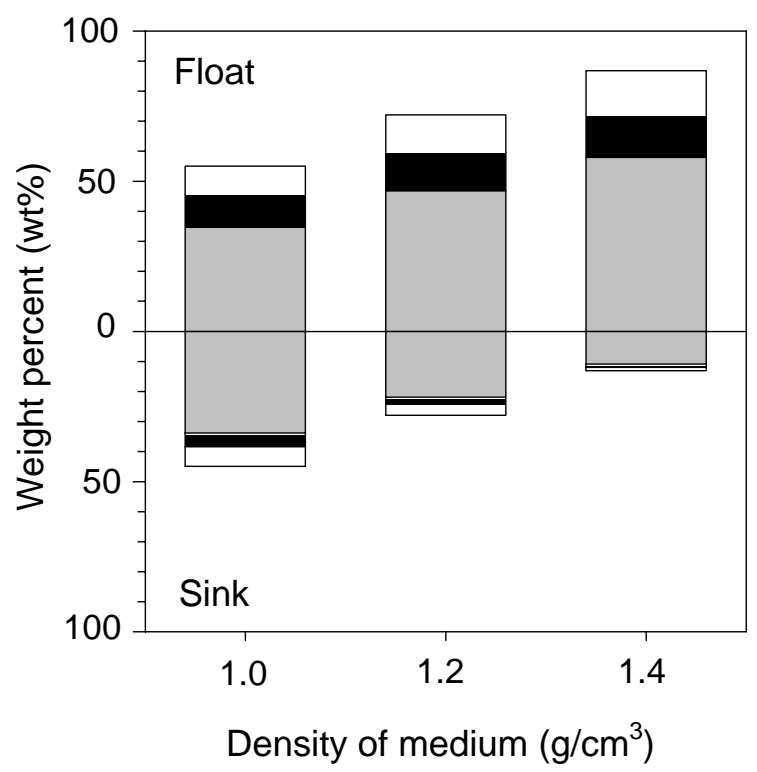

(a) Float-sink separation, L/S $=30$.

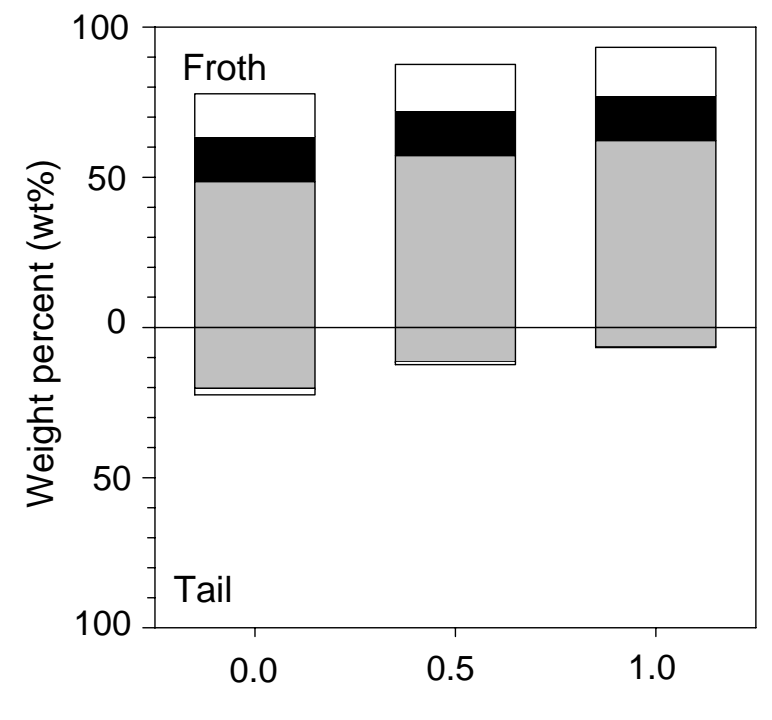

Addition amount of kerosene ( $\mu \mathrm{l} / \mathrm{g}$-char)

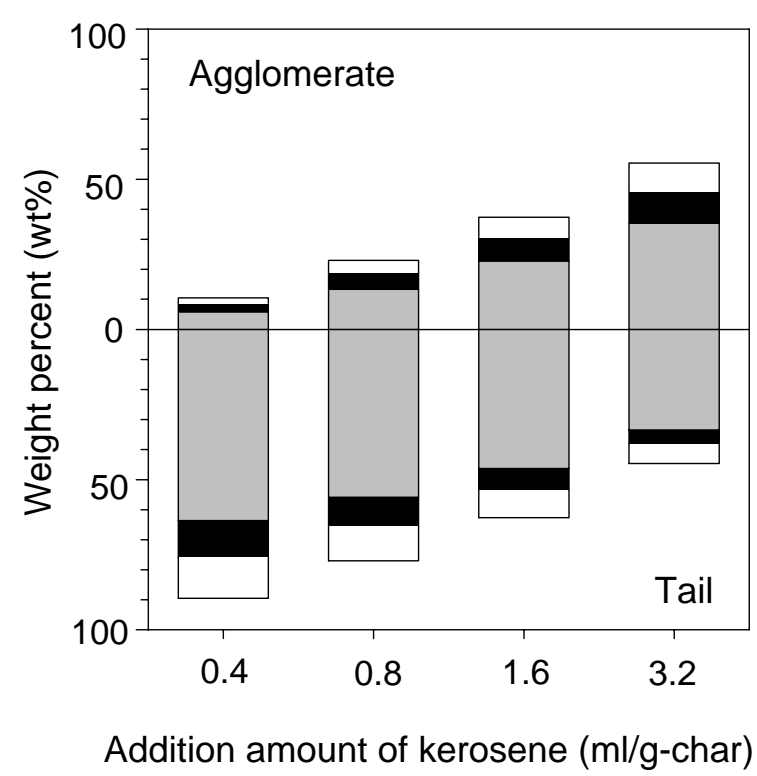

(c) Oil agglomeration.

Volatile matter

Fixed carbon

Ash

Figure 3. Mass balance and composition of recovered- and rejected ASR char by the application of float-sink separation, froth floatation, and oil agglomeration. 

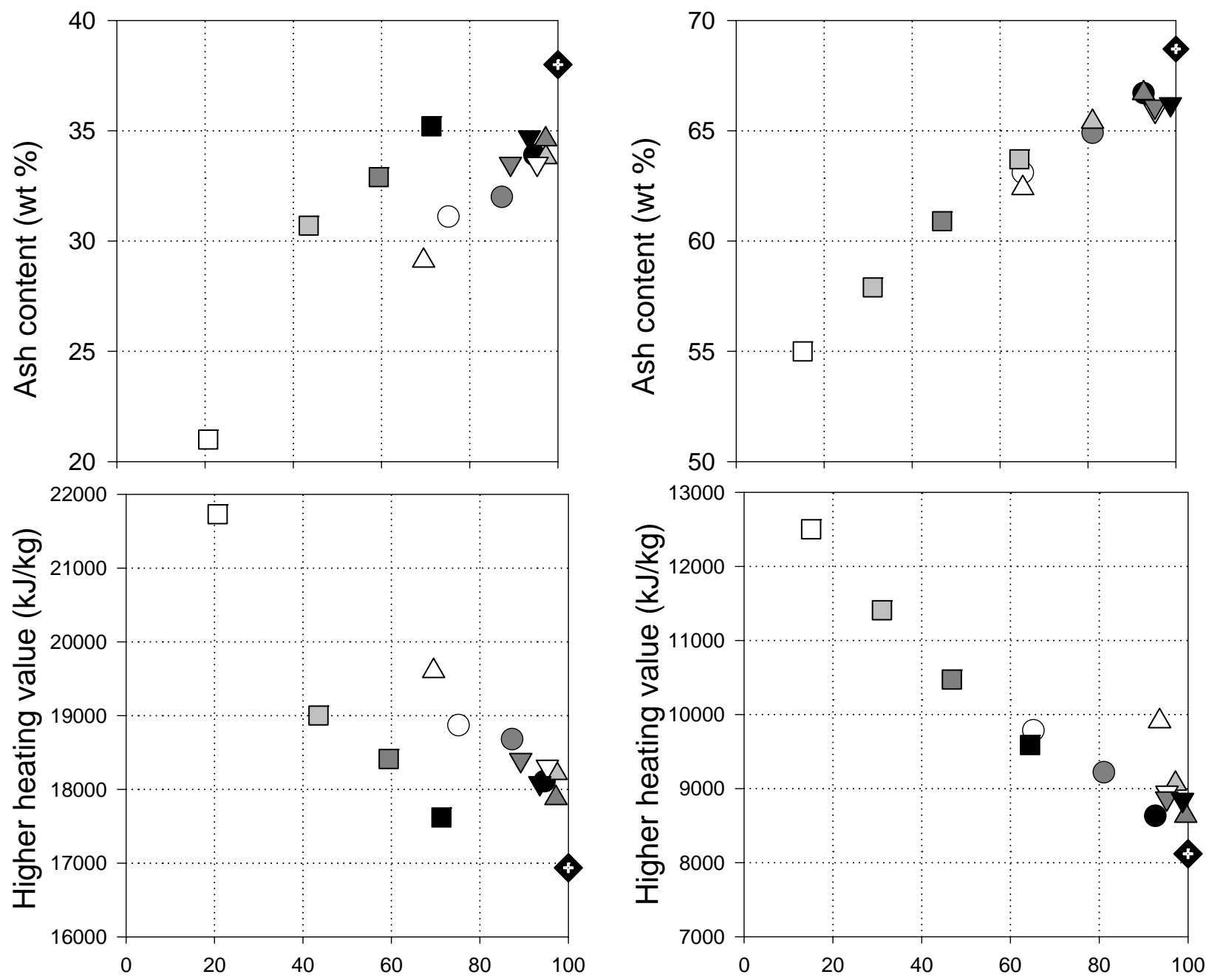

Rate of combustibles recovery (\%)

Rate of combustibles recovery (\%)

(a) MSW char

(b) ASR char

$\uparrow$ Char under $125 \mu \mathrm{m}$

$\begin{array}{llll}\bigcirc[F S, 1] & \triangle[F F, 1,0] & \nabla[F F, 3,0] & \square[O A, 0.4] \\ \bigcirc[F S, 1.2] & \triangle[F F, 1,0.5] & \nabla[F F, 3,0.5] & \square[O A, 0.8] \\ \bigcirc[F S, 1.4] & \triangle[F F, 1,1] & \nabla[F F, 3,1] & \square[O A, 1.6] \\ & & & \square[O A, 3.2]\end{array}$

[FS, \#]: [Float-sink separation, medium density $\left(\mathrm{g} / \mathrm{cm}^{3}\right)$ ]

[FF, \#, \#]: [Froth floatation, char input concentration (wt\%), kerosene amount ( $\mu \mathrm{l} / \mathrm{g}$-char)]

[OA, \#]: [Oil agglomeration, kerosene amount (ml/g-char)]

Higher heating values were estimated by equation 2 .

Figure 4. Ash content and higher heating value of recovered char versus rate of combustible recovery depending on coal cleaning method. 

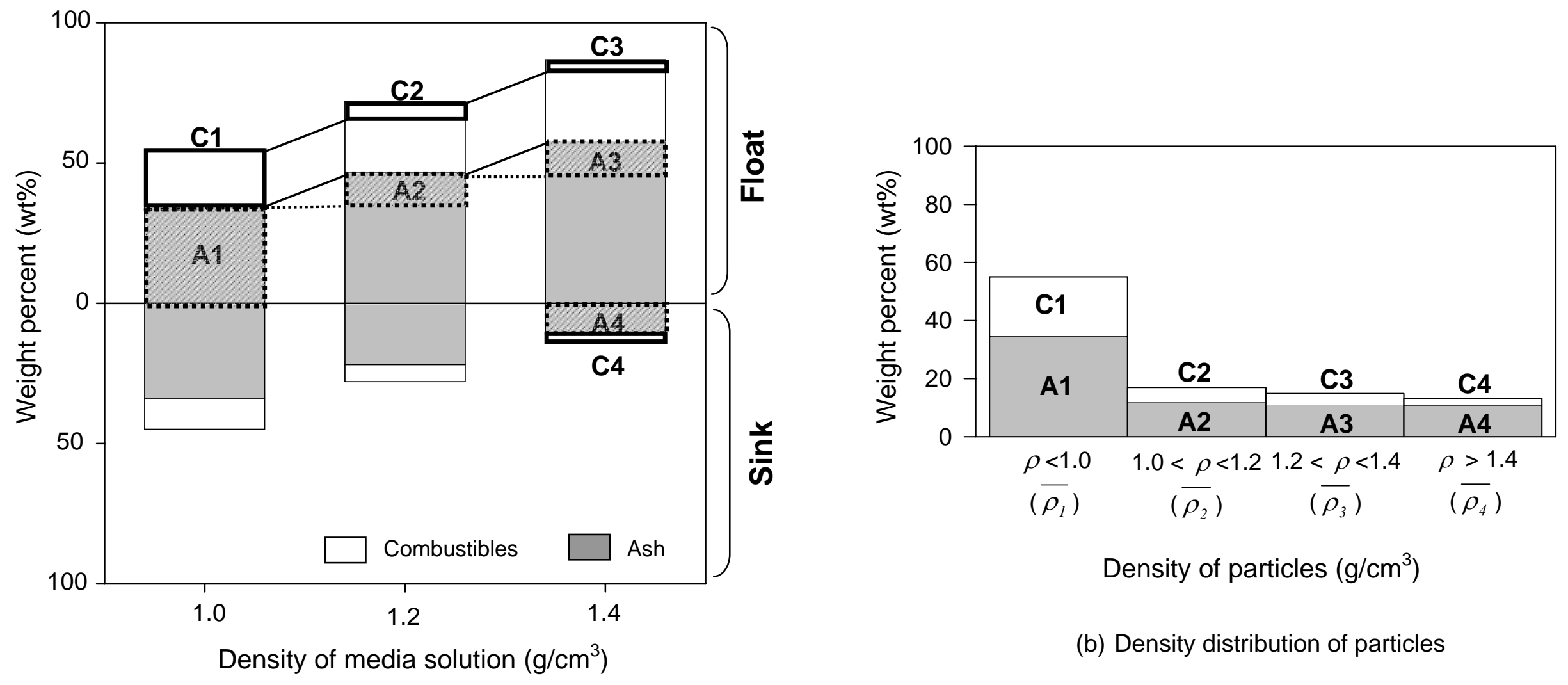

(b) Density distribution of particles

(a) Sinks and floats under media with a density of $1.0,1.2$, and $1.4 \mathrm{~g} / \mathrm{cm}^{3}$

Figure 5. Estimated density of combustibles and ash in the ASR char using proximate analysis data of float and sink divided in media with densities of $1.0,1.2$, and $1.4 \mathrm{~g} / \mathrm{cm}^{3}$ at $\mathrm{L} / \mathrm{S}=30$. 


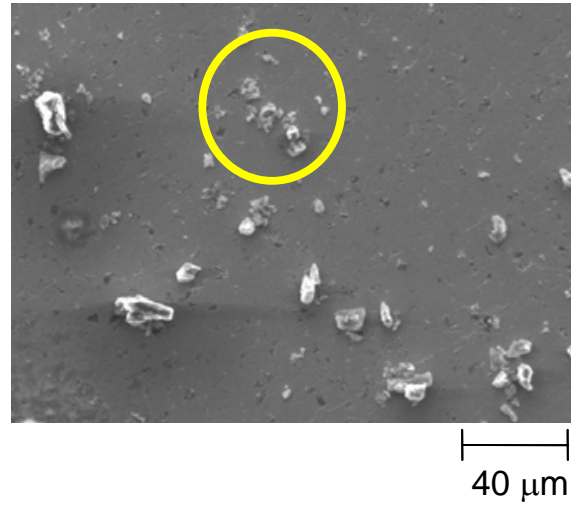

(a) MSW char $(\times 300)$

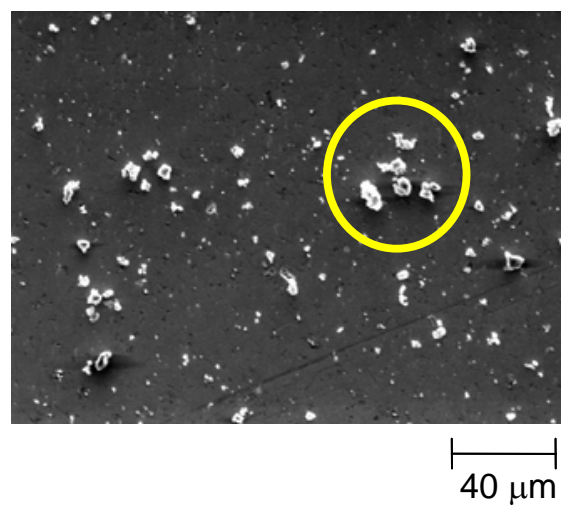

(d) ASR char $(\times 300)$

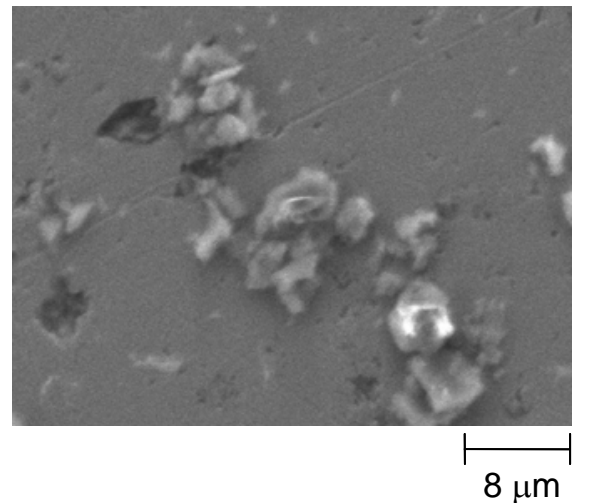

(b) MSW char $(\times 1500)$

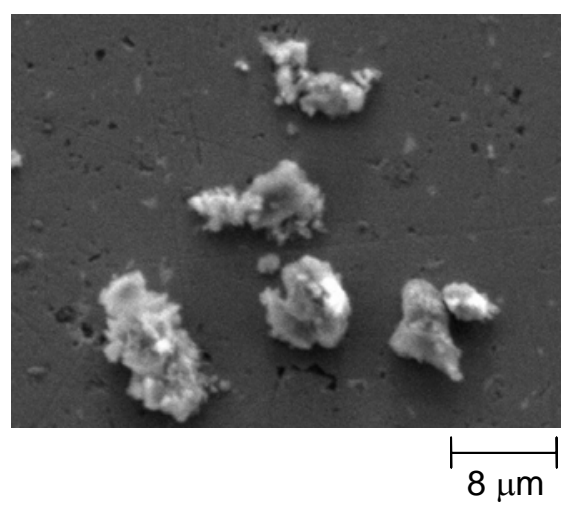

(e) ASR char $(\times 1500)$

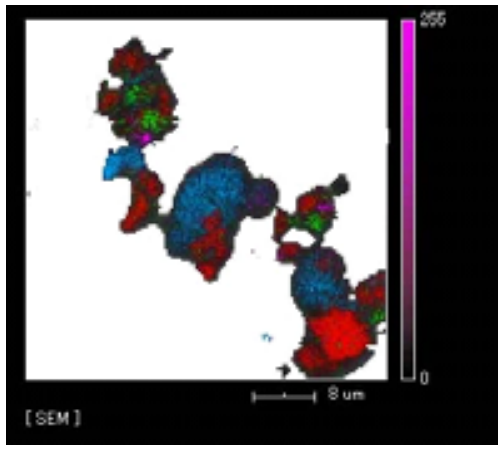

(c) EDX image of MSW char $(\times 1500)$

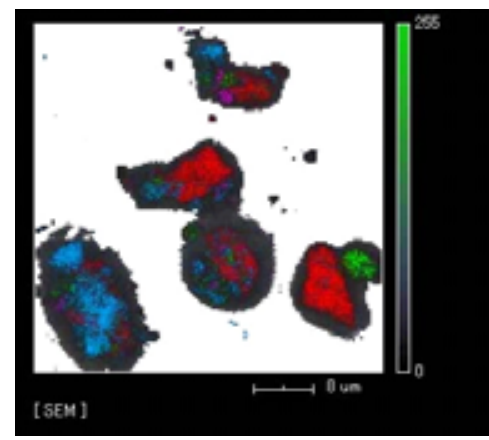

(f) EDX image of ASR char $(\times 1500)$

\section{Osi Oca Ofe OAl Oc}

Figure 6. SEM/EDX images of MSW and ASR char under $125 \mu \mathrm{m}$. 


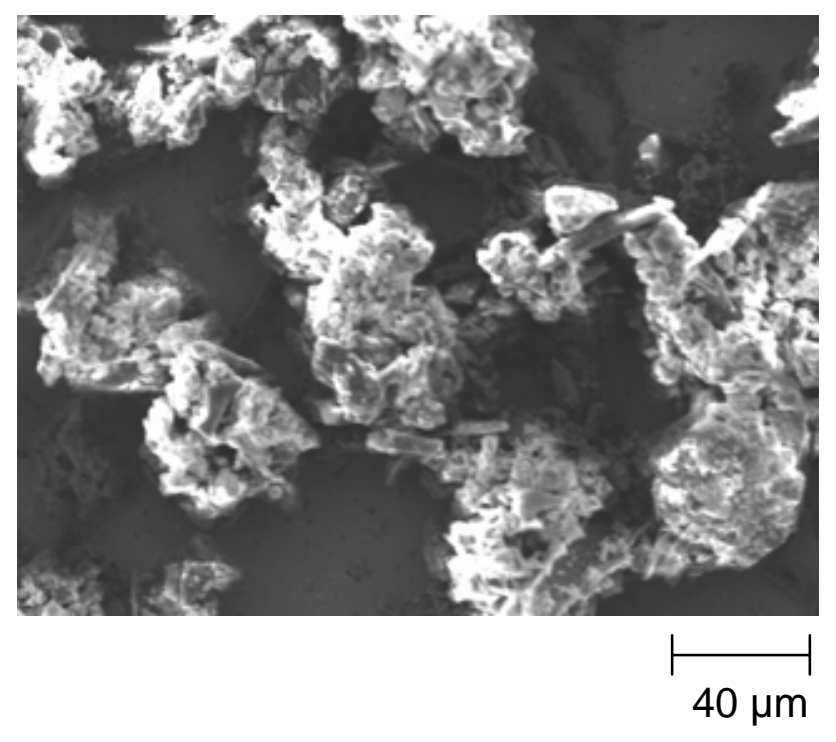

(a) MSW char $(\times 300)$

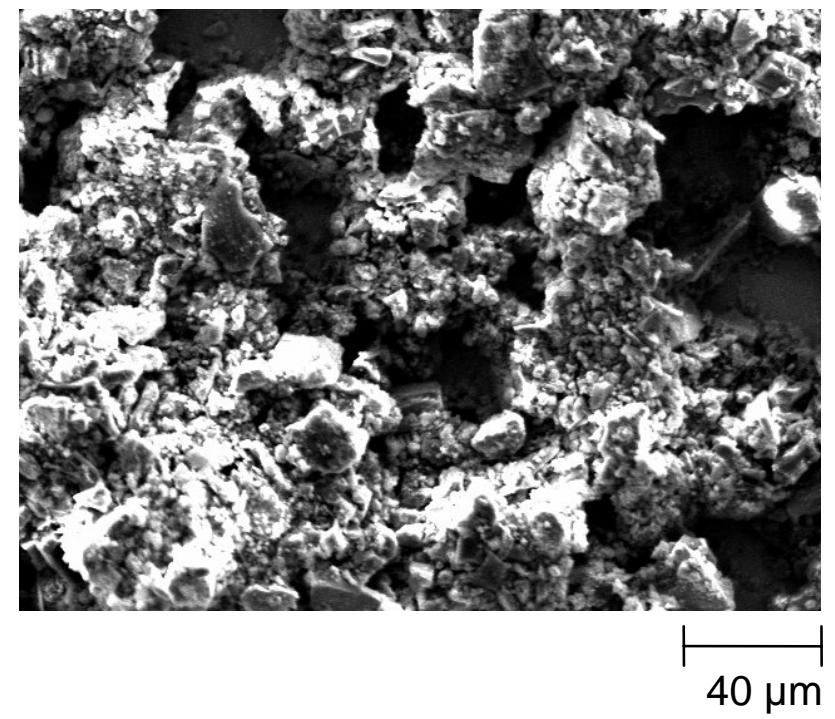

(b) ASR char $(\times 300)$

Figure 7. SEM images of MSW and ASR char under $125 \mu \mathrm{m}$ after immersion in water. 